\title{
John William Powles obituary (1943-2018)
}

\author{
Carol Brayne ${ }^{1}$, Hebe Gouda ${ }^{2}$ \\ 'Department of Public Health and Primary Care, University of Cambridge, UK \\ ${ }^{2}$ World Health Organization, Geneva, Switzerland
}

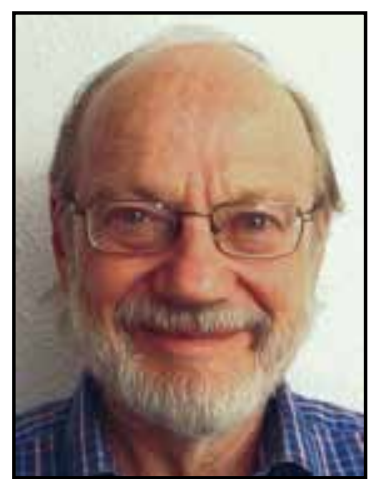

ADDRESS FOR CORRESPONDENCE: Prof. Carol Brayne, Department of Public Health and Primary Care, University

of Cambridge, UK, e-mail:cb105@medschl.cam.ac.uk

Dr John William Powles passed away on 15 September 2018. John grew up in rural Australia, in the Riverina region of New South Wales (NSW), and studied Medicine at the University of Sydney.

At University, John was a keen advocate for social justice. He founded the Sydney University Humanist Society, which was involved in the Campaign for Nuclear Disarmament. In 1965 he was the Vice-President of the group 'Student Action for Aborigines' (SAFA), led by Charlie Perkins, the first aboriginal student to graduate from Sydney University. The group organised the 'SAFA bus tour', also known as the 'Freedom Ride', around regional New South Wales, modelled on civil rights actions in the United States. That helped to prompt public debate on racism and had influence on aboriginal rights recognition.

In 1966, John's interest in global cultures took him on a study tour to China in the midst of the Cultural Revolution, with a group of other young Australians and New Zealanders. John graduated from Sydney University in 1968. After his training as a junior doctor in Sydney, he married his first wife, Margaret Fisher, and travelled to the UK, where he remained for four years as a research fellow at the Centre for Social Research, University of Sussex. In 1973, his paper 'On the Limitations of Modern Medicine' was published in Science, Medicine, and Man (shortly thereafter referenced in Ivan Illich's 'Medical Nemesis'). This early paper reveals many of the ideas and broad interests John maintained throughout his life, including mortality trends, health consequences of transitions, diseases of civilisation, food and nutrition, and health costs and benefits. The paper also shows his characteristically insightful analysis, drawing on knowledge ranging from human evolution to historical demography, social science, philosophy, policy, history, and economics.
Returning to Australia in 1975, he took up a lectureship at the Department of Social and Preventive Medicine at Monash University in Melbourne. During the 1980s he led a landmark programme of research, The Levkadian Migrant Health Study, aimed at explaining the effects of diet on the persisting low mortality of Greek migrants to Australia. In the early 1990s, John helped to establish the Melbourne Collaborative Cohort Study to investigate the roles of diet and lifestyle in causing cancer and other non-communicable diseases, contributing later to findings supporting the health benefits of the Mediterranean Diet.

In 1990 John travelled again to China as a member of the Epidemiology Delegation led by Lester Breslow, in the context of a 'People to People Citizen Ambassador Program', where he met his second wife. In 1991 he emigrated to the UK, taking up a University Lectureship in Public Health Medicine at Cambridge. There he developed and guided the TEMPUS project to support the development of public health disciplines in Bulgaria. At the end of the 1990s he pioneered the establishment of the first stroke register in Central and Eastern Europe in the Varna region and developed, with Bulgarian colleagues, the Varna Diet and Stroke Study, funded by the Wellcome Trust. In the years 2003-2005 he was engaged in the preparation of a report on the health situation in Eastern Europe. He was appointed senior lecturer at the University of Cambridge in 2002.

In the new century, he continued his studies in understanding differences in mortality and in cardiovascular diseases, always with an eye open to comparisons between the East and the West. With his long-term friend Anthony McMichael, John worked on a better understanding of the impact of our dietary behaviours not only on population health, but also the health of 
the planet, bringing the link between the consumption of meat and climate change into the public health arena. At this time, he also led seminal research on the burden attributable to salt/sodium intake within the Nutrition and Chronic Diseases Expert Group, providing the basis for the estimates produced for the Global Burden of Disease 2010 and onwards.

In recent years John was excited by the potential of institutional economics as a framework for better understanding of public health transitions. He believed that public health had much to learn from comparative analysis of the divergent histories of the former communist countries of Eastern Europe, Western Europe, and countries like the USA and Australia.

With John's death, public health has lost not only a great intellectual contributor, but also a passionate and kind educator. His enthusiasm and advocacy for public health was most evident in his teaching and culminat- ed in the establishment of the MPhil in Public Health at Cambridge, where he continued to teach even after his retirement in 2011, having then moved to Spain. Through his work he inspired countless students around the globe.

John stayed active and enjoyed life throughout retirement. He suffered a heart attack as he was swimming. He is survived by his wife Adela, his daughter Rebecca, and grand-daughter Sylvia.

\section{ACKNOWLEDGEMENTS}

The article was prepared by Carol Brayne, Hebe Gouda, Rebecca Hill, and Adela Powles on the basis of John's obituary, which will be published in the "British Medical Journal".

\section{DISCLOSURE}

The authors report no conflict of interest. 